JABE, Volume 21, Number 2, 2021

ISSN: 1542-8710

\title{
THE ETHICS OF ROBOTS AND ARTIFICIAL INTELLIGENCE
}

\author{
Douglas Petrikat, Charisma University, Turks \& Caicos Islands \\ Peng Chan, California State University-Fullerton, U.S.A. \\ Nasim Hosein, Norwich University, U.S.A.
}

dx.doi.org/10.18374/JABE-21-2.5

\begin{abstract}
The increasing presence of robots and artificial intelligence (AI) is a major development affecting individuals, organizations, and nations. How we work, shop, commute, are entertained, provide healthcare and conduct warfare are all affected. There is an awareness of both positive and negative aspects of this development. Public perception of the ethics of robots and Al will impact how effectively organizations and government can utilize such technology. This paper examines these issues and how trends in this field could be affected.
\end{abstract}

Keywords: Robots; Artificial Intelligence; Ethics 